\title{
Some Forensic Aspects on Drug-Facilitated Sexual Assault
}

\author{
Vinod Dhingra* \\ Senior Scientific Officer, Regional Forensic Science Laboratory, India \\ *Corresponding author: Vinod Dhingra, Senior Scientific Officer, Regional Forensic Science Laboratory, Gwalior-474001, India
}

Submission: 㭰 March 24, 2018; Published: 眥 May 14, 2018

\begin{abstract}
The society is undergoing drastic social changes at a very rapid pace. These changes have made the old techniques of criminal investigation obsolete. The field of activities of the criminal is widening at a terrific rate. The analysis can be no better than physical evidence analyses. The clue material has to be identified positively; otherwise the evidentiary value of the clue is limited. Drug-facilitated sexual assault is not a new phenomenon. The use of alcohol can be traced back in human history for thousands of years as it has been used widely for religious, social and medicinal purposes. Flunitrazepam, Ketamine and GHB (gamma hydroxy butyrate) have recently become dangerously popular and are being used to facilitate sexual assault especially in high profile parties. This study highlights usage of newer drugs in sexual assault cases, their forensic aspects collection of physical evidences from crime scene, suspects and victims.
\end{abstract}

Keywords: Flunitrazepam; GHB; Ketamine; Drugs; Sexual assault

\section{Introduction}

The society is undergoing drastic social changes at a very rapid pace. These changes have made the old techniques of criminal investigation obsolete. The field of activities of the criminal is widening at a terrific rate. The analysis can be no better than physical evidence analyses. The clue material has to be identified positively; otherwise the evidentiary value of the clue is limited. Drug-facilitated sexual assault is not a new phenomenon [1-3]. The use of alcohol can be traced back in human history for thousands of years as it has been used widely for religious, social and medicinal purposes. Flunitrazepam, Ketamine and GHB (gamma hydroxy butyrate) have recently become dangerously popular and are being used to facilitate sexual assault. These drugs are widely available and will not only sedate a woman in order to facilitate a sexual assault, but also have an amnesic-like effect so that the victim has little or no memory of the rape when it is over. Alcohol is still the primary drug of choice. The techniques being used to investigate these "date rape drugs" can also be applied to alcohol and any drug used to facilitate sexual assault $[4,5]$. Alcohol is a sedative and should never be dismissed by law enforcement agencies as an insignificant drug. The danger of taking alcohol and a drug together is well known due to synergistic effect. In many fatal cases, less than individually lethal amounts of either are found, and they may even potentiate each other's action. The effects of these drugs are similar to those caused by consuming a large amount of alcohol. Depending on the type of drug and the amount ingested, the victim may experience signs of confusion, memory loss, drowsiness, impaired motor skills, impaired judgment, reduced inhibition, slurred speech, or a variety of other symptoms that complicate the investigation.

There are many challenges for investigating sexual assault crimes, especially when the defense is consent. Because of the very nature of most drugs used to facilitate sexual assault, the victim will display symptoms such as impaired motor skills, reduced inhibition, drowsiness, and memory loss, all of which contribute to a victim's lack of physical resistance, inconsistent statements and delayed reporting. This study highlights usage of newer drugs in sexual assault cases, their forensic aspects collection of physical evidences from crime scene, suspects and victims.

\section{List of Drugs}

Following drugs have been reported in the literature to be used, in drug-facilitated sexual assault cases they are 1,4-Butanediol dextromethorphan, methamphetamine, alprazolam, diazepam, morphine, amitriptyline, diphenhydramine, oxazepam, amobarbital, doxepin, oxycodone, amphetamine, doxylamine, paroxetine, butalbital, ethanol, pcp, carisoprodol, flunitrazepam, pentobarbital, chloral hydrate, fluoxetine, phenobarbital, chlordiazepoxide, ghb, propoxyphene chlorpheniramine, hydrocodone, scopolamine, citalopram, hydromorphone, secobarbital, clonazepam, imipramine, sertraline, clonidine, ketamine, thc, cocaine, mdma, triazolam, codeine, meprobamate, valproic acid, cyclobenzaprine, methadone and zolpidem. 


\section{Collection of Physical Evidences from Crime Scene, Suspects and Victims}

Law enforcement agencies must be aware of the signs of a drugfacilitated sexual assault so that they can properly document and collect physical evidences and help the victim to decide if a "full drug screen" is necessary. This is particularly essential in cases where GHB, Flunitrazepam, Ketamine and other "date rape drugs" may have been surreptitiously given to the victim. The first responding officer should secure and collect urine sample for toxicological testing if it is suspected that a drug was ingested within 96 hours. If the drug was ingested within 12 hours, the victim should also be transported to the nearest medical facility to obtain a blood sample.

The investigator must carefully deduce from the types of drugs used to facilitate the sexual assault, the effects these drugs had on the victim, and an account of the events surrounding the actions of everyone involved. The crime scene investigator may be the first to suspect the victim was drugged to facilitate a sexual assault from the victim's urine and blood screened as soon as possible for traces of Flunitrazepam and their metabolites, GHB, Ketamine and any other possible drugs. Vomit should be collected in addition to the urine and blood specimens. To assist the toxicologist, the investigating officer should be diligent in properly documenting their case. During investigation note what drugs-voluntarily or involuntarily were ingested in the last five days-that might have incapacitated or contributed to the incapacitation/vulnerability of the victim. Keep in mind that in a drug-facilitated rape case, more than one drug may have contributed to the incapacitation/vulnerability of the victim. Evidences before submitted for conducting a "Full Drug Screen," in forensic toxicology laboratory it should be confirmed that the laboratory is testing the urine and blood samples for: Benzodiazepines, Amphetamines, Muscle relaxants, Cocaine, Marijuana, Barbiturates, Opiates, Antihistamines, Ethanol, Sleep aids and any other substance that depresses the central nervous system.

The crime scene related to a drug-facilitated sexual assault may contain physical evidences like packages of Flunitrazepam and other drugs, Empty bubble packages and other material in which drugs could be packaged, precursors/reagents, prescriptions paper of sleeping aids, muscle relaxants, and sedatives, liquor bottles, mixers, punch bowls-look for drug residue, containers for GHB, glasses, soda cans and bottles any containers for any residue of drugs, possible vomit from the victim-may be a source of drug residue, video/camera equipment, videotapes, photographs, and compact disk of sexual assault victim, pornographic literature containing suggestions of drugging women to facilitate sexual assault, Internet information/pamphlets on Flunitrazepam and GHB and on using these and other drugs in the commission of sexual assaults or for other purposes, computers and computer discs.

Depending on the case and its facts, a suspect forensic examination for evidence of the crime should be considered. Performing a suspect examination is sometimes disregarded in drug-facilitated sexual assault cases because the report of the assault is delayed and no evidence is likely to be found on the suspect after several days have passed since he committed the sexual assault.

The role of expert testimony in drug-facilitated sexual assault cases cannot be underestimated. Chemists, forensic toxicologists, and pharmacologists historically have testified in drug trials about their analyses of the particular drug or drugs involved in the case at trial. In a drug-facilitated sexual assault trial these experts will also testify about their analyses of the drug used to rape the victim. In addition to that testimony, these experts can testify how the particular drug affects the body in general, how the victim's symptoms are typical of someone who has ingested this drug, and can explain the lack of a positive toxicological result in the case. A forensic toxicologist will also be able to testify to possible reasons for a negative result, such as the lapse of time between ingestion and collection of the sample. To explain the properties or effect of the drug, testimony from a scientist with a pharmacological background, who will know more about how the drug works in the body, may be necessary. In the case of negative toxicology results, the pharmacologist can explain that the symptoms experienced by the victim are "consistent" with being drugged with a drug such as a benzodiazepine like drugs.

\section{Conclusion}

The challenges presented in drug facilitated sexual assault crimes are not insurmountable. Law enforcement agencies have a variety of investigative techniques available in deconstructing these difficult crimes. It is simply a matter of conducting a thorough and creative investigation. Law enforcement agencies must keep an open mind, understand the patterns associated with sexual assault crimes, and use these patterns to strategize the most effective course of investigation. Drug facilitated sexual assault crimes is an extensive problem and even the lowest prevalence includes a huge number of victims. Hence, stringent measures should be taken for the prevention and control of this hidden public serious health and legal issue in any society. Mass media should play an important role by creating awareness among common people for safe guard of girls and women about accepting drink from tamper-proof bottles and cans, not accepting drinks from unknown persons. In parties sharing or exchange drinks with anyone should be avoided and drink should not remain unattended while talking, dancing, using the restroom, or making a phone call etc to avoid drug facilitated sexual assault crimes.

\section{References}

1. Kuhn C, Swartzwelder S, Wilson W (1998) Buzzed; the straight facts about the most used and abused drugs from alcohol to ecstacy. WW Norton \& Company, New York/London, USA.

2. LeBeau M (1999) Recommendations for toxicological investigations of drug-facilitated sexual assaults. J Forensic Sci 44(1): 227-230.

3. (2016) Modi's medical jurisprudence and toxicology, $\left(25^{\text {th }}\right.$ edn $)$.

4. Weir E (2001) Drug-facilitated date rape. CMAJ 165: 80.

5. Welch J, Mason F (2007) Rape and sexual assault. BMJ 334: 1154-1158. 
Creative Commons Attribution 4.0 International License

For possible submissions Click Here

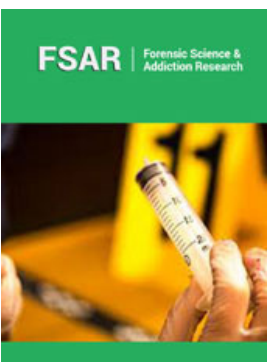

Forensic Science \& Addiction Research

\section{Benefits of Publishing with us}

- High-level peer review and editorial services

- Freely accessible online immediately upon publication

- Authors retain the copyright to their work

- Licensing it under a Creative Commons license

- Visibility through different online platforms 